4. To provide educational information on healthy eating/further weight management options.

Methods Children aged two years or older attending the Emergency Department were identified. Parents completed a survey indicating the perceived weight status of their child. The height and weight of the child were recorded, and the BMI and standardised body mass index (BMI SDS) were calculated using the 'Measure Me' phone application and communicated to the parents. Children were offered a 'Healthy Ireland' food pyramid sticker. Parents of those overweight/ obese children identified were provided with details to be referred onto Temple Street Hospital Outpatient Services for further weight management.

Results 101 children in total participated. 17.8\% (18/101) were classified as overweight/obese, with a standardized BMI above the $91^{\text {st }}$ centile. Of those overweight/obese; 50\% $(9 / 18)$ of parents incorrectly identified their child to be of normal weight status. Of the parents who accurately identified their child as overweight (9/18), 77.8\% (7/9) indicated they perceived their child to be 'mildly' overweight. Objectively $85.7 \%(6 / 7)$ of these were obese with a BMI SDS above the $95^{\text {th }}$ centile. In total $83.3 \%(15 / 18)$ of the overweight children had a standardized BMI above the $95^{\text {th }}$ centile. $83.3 \%(15 / 18)$ of overweight/obese children accepted educational information. Conclusion In keeping with Queally M. et al.'s study a large proportion of children were objectively overweight/obese with a BMI SDS above the $91^{\text {st }}$ centile. However half of the parents failed to accurately identified their child's overweight/obese status. Although the remainder of parents accurately identified their child as overweight, a large proportion indicated that they perceived their child to be 'mildly overweight'. The vast majority of these children were obese with a BMI SDS above the $95^{\text {th }}$ centile. The high rates of parental acceptance of educational information would suggest a willingness to be further educated on weight optimization in children.

\section{P658 ASSOCIATION OF SEVERE VIRAL BRONCHIOLITIS DURING INFANCY AND EARLY LIFE WITH DEVELOPMENT OF RECURRENT WHEEZE}

Helena Živić*. Health facility Zagreb Center, Zagreb, Croatia

\subsection{6/archdischild-2019-epa.988}

Introduction Respiratory viral infections in infancy and early life, especially with allergic sensitization, are associated with higher risks of developing recurrent wheeze and asthma.

Objective To analyze the association of viral bronchiolitis in infancy and early life with development of recurrent wheeze.

Design and participants Retrospective study of children younger than 1 year, in our primary care setting, treated for bronchiolitis during 3 consecutive fall to winter seasons (2014-2016). Causative viruses of bronchiolitis were RSV and rhinovirus species. Development of recurrent wheeze (as defined in national asthma guidelines) by age 3 years.

Results 100 infants who were treated for RSV or rhinovirus bronchiolitis. The median age was 3 months (range 1-7 months), 42 (42\%) had RSV bronchiolitis, 58 (58\%) had rhinovirus bronchiolitis. $42(42 \%)$ had IgE sensitization, of which $14(33.3 \%)$ to food, $18(42.9 \%)$ to aeroallergens, $10(23.8 \%)$ to food and aeroallergens combined. Overall, 39 (39\%) developed recurrent wheeze by age 3 years. There was a significant interaction between viral bronchiolitis and $\operatorname{IgE}$ sensitization on the risk of recurrent wheeze. All children who developed recurrent wheeze also had $\mathrm{IgE}$ sensitization.

Conclusions Infants with both bronchiolitis and IgE sensitization (to food or aeroallergens) had significantly higher risks of recurrent wheeze with subsequent development of asthma at age 3 years. It identifies infants at higher risk so we can introduce preventive measures, and enhanced follow-up.

\section{P659 CORNELIA DE LANGE SYNDROME AND SPONTANEOUSLY REGRESSIVE BRONCHOGENIC CYST ABOUT A UNUSUAL CASE}

${ }^{1}$ Faiza Safi, ${ }^{1}$ Sahar Trichilli, ${ }^{1}$ Manel Hsairi, ${ }^{1}$ Lamia Gargouri, ${ }^{2}$ Chiraz Regaieg*, ${ }^{3}$ Mahdi Ben Dhaou, ${ }^{2}$ Abdellatif Gargouri, ${ }^{3}$ Riadh Mahiri, ${ }^{1}$ Abdelmajid Mahfoudh. ${ }^{1}$ Pediatric Emergency and Resuscitation Pediatric Service, Hedi Chaker Hospital, Sfax, Tunisia; ${ }^{2}$ Neonates Intensive Unit Care, Hedi Chaker Hospital, Sfax, Tunisia; ${ }^{3}$ Pediatric Surgery Department, Hedi Chaker Hospital, Sfax, Tunisia

\subsection{6/archdischild-2019-epa.989}

Introduction Cornelia de Lange syndrome is characterized by intra uterine and postnatal growth retardation, developmental disorder, facial dysmorphism, hypertrichosis, and organ malformations. The association with a bronchogenic cyst is unusual. Case report This is an 8-month-old male, born at term from a non-consanguineous marriage. He was hospitalized twice for recurrent pneumonitis. It was addressed for further exploration.On clinical examination, he had microcephaly, a low set of hair on the forehead, arched and confluent eyebrows, long eyelashes, a wide nose root, anteverted nostrils, a long and bulging philtrum, a mouth falling at the corners and a very thin upper lip, a low implantation of the ears and a microretrognatism. He was puny with a weight loss of -4 DS. Biologically, the infectious balance was negative.An abdominal ultrasound performed was without abnormalities as well as the transfontanellar ultrasound. A thoracic CT showed a large right mediastinal hilar cystic mass measuring $69 \times 68 \times 44 \mathrm{~mm}$ with fluid density and regular clean wall enhanced after injection of contrast agent dealing with a bronchogenic cyst. The therapeutic abstention was opted. The evolution was marked by the spontaneous regression of the cyst.

Conclusion Cornelia De Lange syndrome is rare with variable severity. The association with bronchogenic cyst which had spontaneously regressive evolution is a rare entity.

\section{P660 ABSCESS OF THE KIDNEY, A DIAGNOSIS NOT ALWAYS EVIDENT!}

Faiza Safi, Lamia Gargouri, Manel Hsairi, Chiraz Regaieg*, Bayen Maalej, Abdelmajid Mahfoudh. Hedi Chaker Hospital, Sfax, Tunisia

\subsection{6/archdischild-2019-epa.990}

Introduction Kidney abscess is defined as a suppurate lesion collected in the renal parenchyma. It is a rare pathology in pediatrics. We report four cases of renal suppuration.

Material and method This is a retrospective study over a period of 9 years (2010-2018) collaging all cases of renal abscess having been hospitalized in the pediatric ward, emergency and pediatric resuscitation of Sfax.

Results We collected 4 cases of renal abscess. These were two boys and two girls. The average age was $5 \frac{1 / 2}{2}$ years with extremes ranging from $3 \frac{1}{2}$ years to 10 years. The delay of diagnosis was estimated at an average of 19 days. Fever and 